\title{
THE LEAGUE OF RED CROSS AND RED CRESCENT SOCIETIES (LRCS)
}

Andrei K. Kisselev, M.D., Undersecretary General

Geneva, Switzerland

The "International Red Cross" is composed of: (1) The International Committee of the Red Cross (ICRC) which focuses on war victims; (2) the LRCS; and (3) the 130 National Red Cross and Red Crescent Societies worldwide which are federated by the LRCS. The LRCS was founded to facilitate, encourage and promote the humanitarian activities of its member societies and thus contribute to the promotion of peace in the world. The LRCS considers health as one of the keys to a better world for everyone. Red Cross programs include the training of nursing personnel, the provision of health care in rural areas, the organization of assistance to the sick, aged, and handicapped, and teaching first aid skills to lay people.

The Red Cross bases its actions on seven principles: (1) Humanity; (2) Impartiality; (3) Neutrality; (4) Independence; (5) Voluntary Service, (6) Unity; and (7) Universality.

The LRCS assists national societies in improving their disaster relief preparedness through the following functions: (1) to encourage, facilitate and assist in the establishment of a national disaster relief plan; (2) to give technical assistance to national Red Cross societies by sending delegates and equipment and/or by giving cash grants; (3) to convene seminars and conferences to help exchange opinions and share experiences; (4) to train qualified personnel; and (5) to maintain contact with other international governmental and non-governmental organizations. These include the United Nations Disaster Relief Organization (UNDRO); the World Health Organization (WHO); the International Children's Fund (UNICEF); the World Meteorological Organization (WMO); the Food and Agricultural Organization/World Food Program (FAO/WFP); the UN High Commissioner for Refugees (UNHR); and the United Nations Education Scientific and Cultural Organization (UNESCO). The LRCS has decided to cosponsor this new Journal, as it firmly believes that this Journal will be an instrument for the implementation of the Red Cross principles and objectives.

LRCS Office: Mr. Hans Hoegh, Secretary General, League of Red Cross and Red Crescent Societies, P.O. Box 276, 1211 Geneva 19, Switzerland, Tel: 345580.
The International Committee of the Red Cross (ICRC), with which the LRCS is associated, provided the following recent report:*

Aiding war wounded is a legal right. International humanitarian law, born of the horror of war, was originally intended to remedy the shortcomings of armed forces medical services. Only one year after the founding of the ICRC, the 1864 Geneva Convention gave protection to doctors and nurses on the battlefield. With time, four Geneva Conventions and two Protocols evolved, codifying and developing that protection.

The Geneva Convention of 1949 provided protection for medical personnel of armies and the personnel of relief societies helping the military medical corps, all of whom were to wear an official emblem (red cross-red crescent) for identification. The 1949 Diplomatic Conference did not feel that civilian medical personnel, other than those of the societies for the relief of the sick and wounded, should be protected and authorized to wear such an emblem. However, a variety of charitable medical associations would like to have the benefit of protection identical to that which international humanitarian law affords the Red Cross, since modern conflicts frequently affect civilians as much as soldiers. It therefore appears necessary to extend legal protection to all civilian medical personnel. A charter was presented at the end of February 1984 in Strasbourg, France during a meeting organized by the International Federation for the Rights of Man and attended by some 30 non-governmental organizations. It will shortly be submitted to the Council of Europe and the United Nations, with a view to the drafting of a new international treaty. The charter demands recognition of two rights: (I) the right of any civilian to be tended by competent and impartial medical personnel, and (II) the medical personnel's right to protection during their missions. Only 38 States have acceded to Protocol I and 32 to Protocol II, whereas 155 States are party to the Geneva Conventions.

*ICRC office: Chief Medical Officer, International Committee of the Red Cross, 17 Ave de la Paix, 1211 Geneva, Switzerland, Tel: 346001 . 